\title{
VIDA DANIFICADA E DECLÍNIO DA EXPERIÊNCIA (ERFAHRUNG): UM DIAGNÓSTICO CONTEMPORÂNEO
}

\author{
Ademir Henrique Manfré \\ Universidade do Oeste Paulista - UNOESTE, FACLEPP, Presidente Prudente, SP. E-mail: ademirmanfre@yahoo.com.br
}

\section{RESUMO}

O presente artigo compõe parte de nossa pesquisa de doutorado em educação finalizada no ano de 2014. Corresponde, portanto, a um recorte do estado do conhecimento em educação e filosofia. Ainda que, nos limites deste artigo, as múltiplas dimensões do estudo mais amplo não sejam objeto de discussão, um aspecto parece necessário à compreensão do presente recorte: o estudo do depauperamento da experiência (Erfahrung) na contemporaneidade, a partir dos filósofos Benjamin e Adorno. Desse modo, o texto objetiva refletir sobre as potencialidades da educação para a formação do indivíduo no contato reflexivo do pensamento crítico com a cultura. Diante do assinalado, serão abordados, neste artigo, alguns elementos constitutivos da experiência no âmbito da educação, bem como os fatores que impedem a emergência dos mesmos, perpetuando assim, nos espaços educativos, a semiformação. Concluímos que, uma educação para a experiência faz sentido enquanto se constituir como elemento que permita a tensão entre adaptação e inadequação, a reflexão, o inconformismo.

Palavras-chave: educação; formação; experiência (Erfahrung); Teoria Crítica.

\section{DAMAGED LIFE AND THE DECLINE OF EXPERIENCE (ERFAHRUNG): A CONTEMPORARY DIAGNOSIS}

\begin{abstract}
This article is part of our PhD research on Physical Education completed in 2014. It is related to a fragment of the state-of-the-art in Education and Philosophy. One important aspect to understand such fragment is the study of the depletion of experience (Erfahrung) in nowadays, from Benjamin and Adorno's standpoint. Thereby, this article aims at reflecting about the potentialities of education to the individual's development in reflective contact of the critical thinking to the culture. Thus, we will analyze some constitutive elements of experience in educational context, as well as features that inhibit the emergence of such elements, perpetuating the semi-education in such kind of situations. We believe that an education guided to experience is adequate whilst constitutes itself as an element that enables tension between adaptation and inadequacy, the reflection, and the nonconformity.
\end{abstract}

Keywords: Education; Human development; Experience (Erfahrung); Critical Theory. 


\section{INTRODUÇÃO}

O tema da experiência, ou melhor, do seu depauperamento, assim como outros presentes em Benjamin (1994a) e Adorno (1995) é essencial para se estabelecer uma reflexão sobre as (im) possibilidades educativas em um contexto marcado pela (semi) formação. É sobre essa temática que trata o presente artigo.

A análise de "Experiência e pobreza (1994a)" revela os desatinos do sujeito frente à perda da capacidade de experienciar e narrar. O referido artigo objetiva elaborar uma reflexão acerca do empobrecimento da experiência (Erfahrung) na atualidade, demonstrando o modo como a subjetividade foi se instrumentalizando de acordo com a sociedade tecnológica.

De modo geral, experiência, enquanto efeito ou ato de experimentar, significa prática de vida, no sentido de se possuir habilidade, prática adquirida com a dedicação constante a uma profissão ou ofício.

Com o advento da Modernidade, experiência significa prova, demonstração, tentativa, modelo.

Em Benjamin (1994a), experiência (Erfahrung) toma outros sentidos.

Com base nos textos "Experiência e pobreza" e "Sobre alguns temas em Baudelaire" é possível apontar alguns elementos que caracterizam o conceito de experiência o qual privilegiamos neste artigo.

Benjamin (1994a) inicia o texto narrando uma fábula conhecida em Esopo (século VI a.c.) em que um pai, agonizante no seu leito de morte, comunica a seus filhos que em suas terras há um grande tesouro. O pai vem a falecer; os filhos cavocam toda a terra da maneira como podem e não encontram tesouro algum. Mas, a força de ter revolvido o terreno, as colheitas foram frutíferas e eles enriqueceram. Ou seja, essas histórias narradas tinham um sentido exemplar, eram ensinamentos transmitidos de geração a geração, o que nos orientava na vida e no pensamento.

À luz do que o próprio Benjamin (1994a) sinaliza em seus textos, esse tipo de experiência torna-se empobrecida nas sociedades modernas, onde as pessoas vivem atomizadas em seus pequenos mundos, enquadradas nos ambientes funcionais da arquitetura contemporânea. Segundo Benjamin, nós não nos ligamos mais ao passado pela tradição. Se quebrou a ideia de tradição, o passado (ou a tradição) não tem mais presença em nosso cotidiano justamente porque vivemos um tempo acelerado e, ao mesmo tempo, contraído de tal forma que o que temos é o advento de um tempo absolutamente vazio. 
Se, como diz o autor, a experiência é entendida como o elo que nos vincula ao passado e a tudo que pertence a ele enquanto patrimônio histórico e cultural e nos encontramos expropriados dessa experiência que nos foi "hipócrita ou sorrateiramente subtraída", resta-nos assumir essa pobreza - traduzida em vivências (Erlebnis), que não é mais privada e sim de toda a humanidade. No entanto, assumir esse empobrecimento da experiência não significa que os homens aspirem a novas experiências: "Não, eles aspiram a libertar-se de toda experiência, aspiram a um mundo em que possa ostentar tão pura e tão claramente sua pobreza externa e interna, que algo de decente possa resultar disso". (BENJAMIN, 1994a, p. 118).

É no ensaio "Sobre alguns temas em Baudelaire", que Benjamin (1994b) apresenta de maneira mais clara a distinção fundamental entre experiência (Erfahrung) e vivência (Erlebnis). O filósofo busca demonstrar de que maneira a vivência (Erlebnis) se tornou na modernidade o único tipo de experiência possível. Benjamin evoca, a partir da lírica de Baudelaire, um conjunto de elementos e conceitos que se vinculam diretamente ao da experiência. O tempo, o trauma, a arte, a alegoria, a memória, a tradição, a vivência do choque na metrópole moderna são faces que caracterizam a discussão acerca da experiência.

O ensaio benjaminiano sobre Baudelaire gira em torno do homem moderno no período de consolidação do capitalismo. A industrialização crescente na era moderna remodela a relação que o indivíduo estabelece também com o trabalho. O operário, tal como a máquina que ele opera, comporta-se automaticamente frente à linha de produção. Seu gesto é sempre uma repetição que obedece aos ritmos que a máquina the dirige, aos comandos por ela suscitados, cabendo ao indivíduo responder, de maneira reflexa e imediata, pelo tempo que the é devido, a esses inúmeros e sucessivos choques.

Talvez o filme "Tempo modernos" de Charles Chaplin traduza o modo como a modernidade inaugura um cotidiano em que o citadino se vê exposto constantemente aos choques da multidão. Se, no trabalho artesanal, o artesão vivia em contato com os ciclos da natureza, dela extraindo elementos para sua experiência, ao indivíduo moderno nada resta, senão uma série de repetições entrecortadas pela imposição de choques advindos da maquinaria industrial. A realidade fotografada por Chaplin é emblemática na apreciação dessa personagem moderna que é o operário nos grandes centros industriais. O que não se pode perder de vista nessa moderna engrenagem das esteiras do trabalho é o estado permanente de tensão diante dos bruscos movimentos da máquina, pois a ameaça de uma mutilação é lembrada a todo instante. Ao operário não resta senão a reprodução dos movimentos do autômato, uma vivência (Erlebnis) nos moldes benjaminianos. 
A esse comportamento irrefletido do operário nas fábricas corresponde o do passante nas ruas da metrópole moderna. Esse aspecto demonstra, de forma bastante drástica, a degradação da experiência na sociedade moderna e capitalista. Ao se modificar a estrutura da experiência, modifica-se também o modo como o indivíduo moderno se relaciona com o tempo, a memória, o espaço, ou seja, modifica-se a sensibilidade. Disso, deriva a tal "crise da percepção" ${ }^{1}$, na qual ao indivíduo resta apenas aparar choques ao que Benjamin (1994b) se refere nesse mesmo ensaio.

As noções de vivência e experiência em Benjamin adquirem um status de conceitos. Veremos como isso se resolve no texto sobre Baudelaire,

[...] a experiência é matéria da tradição, tanto na vida privada quanto na coletiva. Forma-se menos com dados isolados e rigorosamente fixados na memória, do que com dados acumulados e com frequência inconscientes, que afluem à memória. (BENJAMIN, 1989, p. 105).

A citação acima permite delinear, sob múltiplos aspectos, o conceito de experiência em Benjamin. Alguns termos presentes nessa passagem remetem a uma série de outros elementos, tais como a memória, a tradição, o inconsciente, a arte de contar, narrar. Isso quer dizer que a experiência do indivíduo nunca é uma só, nunca está alheia à experiência da história, da tradição, em suma, o indivíduo nunca é um ser isolado da cultura.

Em "Sobre alguns temas em Baudelaire" fica explícito que a experiência é o espaço do tempo e o tempo do espaço. É um tempo completamente oposto ao tempo da vivência, brutal e descontínuo. O tempo da vivência é mecânico e unidimensional, próprio do indivíduo preso à repetição, a exemplo do operário na fábrica, que chega em casa à noitinha e não tem nada a narrar, a contar, pois nada Ihe aconteceu. O tempo da vivência é, desse ponto de vista, um tempo engessado, repetitivo, rígido, sempre igual a si mesmo. Para o indivíduo moderno, o tempo se petrifica, a história não acontece, todos os dias permanecem exatamente iguais uns aos outros.

Na perspectiva benjaminiana, a experiência necessita de uma relação construtiva com o tempo. Para constituir uma verdadeira experiência, o tempo não pode ser apenas uma série de instantes que passam repetitivamente, mas deve criar condições para que os acontecimentos se acumulem formando um sentido apreensível pela memória. Em Benjamin (1994b) fica explícito que a vivência do choque aniquila a possibilidade de reflexão. É a isso que se deve o declínio da experiência na era moderna. O presente, dirá Benjamin (1994b), não converge mais sobre o passado, esse não se vê refletido, interligado ao presente. Desamparado pela experiência antes

\footnotetext{
${ }^{1}$ A experiência contemporânea torna-se esvaziada da sabedoria aclamada por Benjamim, passando a ter uma nova configuração: sua primazia é o instante, a excitação que toma o lugar da experiência. A fugacidade desse novo patamar da experiência pode ser observada no cerne daquele que assume o papel de protagonista da "narração" no capitalismo: o mercado.
} 
oferecida pela tradição, o indivíduo moderno não tem o que ensinar e, consequentemente, a sua possibilidade de aconselhar se perde, bem como sua possibilidade de receber ensinamentos. Não se trata mais de uma experiência duradoura como a do artesão. A experiência do choque substitui o qualitativo pelo quantitativo, em que a durabilidade e a contemplatividade são destituídas do pensamento.

A transformação na estrutura da percepção na modernidade, que por sua vez ocasionou uma grave modificação na estrutura da própria experiência (Erfahrung), também foi objeto de reflexão de Benjamin. Essa metamorfose da percepção é utilizada pelo filósofo para caracterizar o homem moderno, com as intermináveis exposições ao choque e com a incansável tarefa de concentrar suas energias a apará-lo incansavelmente. Trata-se, portanto, dos limites apontados por Benjamin em relação ao progresso desenfreado, à experiência do homem moderno com o tempo, com a memória e com sua história. O tempo do progresso, afirma o filósofo, é o tempo da marcha dos lucros, absoluto e infinito, transposição da linguagem matemática para a história. Na medida em que seu enfrentamento está voltado para o choque, para o idêntico, o homem moderno se torna desprovido de uma remissão mnemônica e tende a uma ação que o alinha a de um autômato. O que resta ao homem automatizado da modernidade?

Diante da amplitude que caracteriza a temática, o objetivo deste artigo é discutir as possibilidades do pensamento reflexivo - mediado pela experiência (Erfahrung) - nas práticas educativas contemporâneas.

\section{METODOLOGIA}

Este artigo, a partir de um estudo qualitativo e bibliográfico, objetiva refletir sobre a degradação da experiência formativa e as possibilidades educativas diante dessa constatação. 0 enfoque principal é o da Teoria Crítica, mais especificamente, os estudos de ensaios de Benjamin (1994a e 1994b) e Adorno (1995). Ambos os autores ressaltam a necessidade da crítica e da tensão entre sujeito e objeto do conhecimento e é a partir dessa questão que se pretende estabelecer algumas reflexões sobre as possibilidades educativas em um contexto marcado pela instrumentalização do pensamento.

\section{RESULTADOS}

Procuramos destacar nesta seção do artigo que o declínio da experiência na escola está intimamente ligado à impossibilidade de se estabelecer uma autorreflexão com a cultura, com o 
pensamento. Da mesma forma, insistimos na autorreflexão, a qual exige um tempo de elaboração do pensamento. No centro da relação do homem com a objetividade, a experiência formativa desempenha importante papel à medida que representa o princípio fundamental pelo qual se assenta o desenvolvimento do indivíduo rumo à formação. Assim, a autorreflexão em Adorno passa pela questão da formação cultural (Bildung). Para o filósofo frankfurtiano, a Bildung não está perdida. Pelo contrário, uma das formas de escapar à reificação da consciência seria sua não absolutização perante a sociedade que a gera. Na "Teoria da Semiformação" lê-se que "a única possibilidade de sobrevivência que resta à Bildung é a auto-reflexão crítica sobre a halbbildung, em que necessariamente se converteu". (ADORNO, 1996, p. 410).

Formação é confronto, tensão. Semiformação é conforme

\section{DISCUSSÃO}

É em Baudelaire - e em seu modo de fazer filosofia - que encontramos uma maneira de tensionar o presente semiformativo. Nos poemas de Baudelaire fica nítida sua revolta, expressa em poemas alegóricos, contra a decadência moderna, contra a depreciação de coisas em mercadorias. Na sociedade administrada, na qual o número tornou-se o cânone do conhecimento, o indivíduo, com seu corpo docilizado, é aquele que visa ao equilíbrio, à imparcialidade, imerso num arcabouço de vivências irrefletidas do mundo da mercadoria. Essa compreensão lógica do mundo se faz no sentido oposto à possibilidade da experiência defendida por Benjamin (1994a e 1995b).

Em Baudelaire, experimentar torna-se uma inversão do que geralmente se conceitua sobre ele: não é um processo fechado, interno, no qual o indivíduo, etapa por etapa, acumula experiência de um modo linear e processual. A experiência é a travessia, é o exterior, e requer abertura, permitir expor-se, conhecer o mundo através da experiência, nomeá-lo e então deixar que a experiência nos atravesse e afete o outro. É na desconstrução, no caminho da abertura às incertezas que a narração pode encontrar fragmentos para o pensamento crítico. Os fragmentos narrativos, aparentemente isolados, ganham contornos novos, que comunicam sentidos e significados a seus interlocutores.

Reconstruir o conceito de experiência elaborado por Benjamin é um processo cuja exigência é proporcional à força de ruptura de seu estilo de pensar: sua historiografia da experiência em sua relação entre o universal e o particular é uma gama de retalhos, fragmentos de experiências intercambiadas através da rememoração. O rememorar da infância, da história, enquanto amálgama de forma e conteúdo de uma narração intercambiadora de experiência, 
compactua, de certa maneira, com as observações de Adorno e Horkheimer (1985) quanto a uma das raízes do problema da razão: sua velha pretensão de dominar a natureza e, por tal, passamos historicamente a realizar nossas experiências sob a forma de dominação da natureza, de si e por si, findando em mecanismos de dominação do outro.

Há então de se pensar nas possibilidades da educação, tendo em vista a experiência como elemento-chave do processo formativo.

Desse modo, a falta de experiência significa um maior poder da racionalidade instrumental sobre a subjetividade, na medida em que se torna fácil impor aos indivíduos, desprovidos de um eu firme, os produtos feitos para o consumo de massa. Essa adesão irracional à totalidade somente é possível porque aquilo que se colocava como referência ou fundamento à reflexão do indivíduo - a tradição, a tensão entre sujeito e objeto, o pensamento crítico, a autorreflexão, a experiência - já não encontra mais espaço na educação atual. Na escola, essa pobreza fica evidente no saber fragmentado, nas metodologias e didáticas reificadoras, no ensino instrumentalizado, no desprestígio do professor enquanto fonte de conhecimento, nas atividades voltadas para o "aprender a aprender constantemente", desvinculadas do aprender a pensar, no tempo administrado com o objetivo de "formar" mais em menos tempo. Não há margem para significação e reflexão do contexto escolar, apenas vivências são permitidas aos indivíduos. Nesse contexto, a ausência da experiência relaciona-se diretamente com a perda da memória, da tradição, do pensamento autorreflexivo.

\section{CONCLUSÃO}

Finalizando, nosso artigo buscou desde o início sublinhar que a pobreza da experiência está ligada à semiformação, ao pensamento instrumental, à ausência do pensamento autorreflexivo. Com isso, retomamos Benjamin (1995a e 1995b) e Adorno (1996) no sentido de tecermos reflexões como possibilidades de tensão, de contradição, de resistência, de formação.

Do mesmo modo que para a formação é essencial que se tenha tempo para experimentar, para tocar, para elaborar, para refletir, para reexperimentar, pensamos que a escola, enquanto lócus privilegiado para a educação, deveria privilegiar o pensamento para a resistência e para a contradição. Para não andar na contramão da formação e da emancipação, caberia à educação reelaborar-se criticamente através de um processo ininterrupto de autorreflexão, consciente de que, no atual contexto, a educação filia-se às exigências do mundo da produção.

Para a possível concretização dos objetivos definidos à educação, julgamos necessária a constatação dos mecanismos sociais que acabam por configurar hoje um cenário de processos 
semiformativos, que fabricam "novas subjetividades" - ou novas formas de dominação e instrumentalização do pensamento, nas palavras de Adorno (1996) - de tal maneira que a experiência formativa não encontra no indivíduo as condições necessárias para se desenvolver. A experiência a qual almejamos interage com o sujeito pela memória, pela história, pela reestruturação de si e é colocada a ele frente às novas experiências. A experiência não é uma relação vertical de um sobre o outro, mas sim a construção-destruição-reconstrução do sujeito e do objeto, que se conectam mutuamente e dali emergem renovadas e permitem a consolidação da experiência.

Pela autorreflexão crítica sobre as consequências do passado sobre o presente, das atrocidades cometidas em nome do progresso e da ciência instrumental, devemos construir meios que possibilitem a resistência à barbárie que ainda persiste. Seria, portanto, um apelo ao nãoelaborado, ao não-reparado que ainda pode nos tocar, nos acontecer, nos passar, mostrando-nos os contrapontos entre o sensível e o irracional e os limites que impedem a formação do pensamento crítico.

A educação, então, guarda seu potencial emancipatório ao manter a tensão inevitável entre adaptação e inadequação, sendo esta última, segundo Zuin (1999), essencial à experiência como necessário distanciamento do fenômeno educativo, para que o pensamento não se reduza no conformismo em uma sociedade que contêm em si elementos de barbárie.

Transformar a pobreza da experiência em experiência seria produzir uma nova experiência, mesmo a partir dessa mesma experiência, como inconformismo e resistência.

\section{REFERÊNCIAS}

ADORNO, T. W. Teoria da semicultura. Tradução de Newton Ramos-de-Oliveira; Bruno Pucci; Claudia B. M. Abreu. Educação e sociedade, n o 56, Campinas, São Paulo: Papirus, dezembro/1996, p. 388-411.

. Educação após Auschwitz. In: Theodor Adorno: educação e emancipação. Tradução de Wolfgang Leo Maar. Rio de Janeiro: Paz e Terra, 1995a, p. 119-138.

BENJAMIN, Walter. Experiência e pobreza. In: Obras escolhidas I. Tradução de Sérgio Paulo Rouanet. São Paulo: Brasiliense, 1994a.

. O narrador: considerações sobre a obra de Nikolai Leskov. In: Obras escolhidas I. Tradução de Sergio Paulo Rouanet. São Paulo: Brasiliense, 1994b.

. Sobre alguns temas em Baudelaire. In: BENJAMIN, W. Charles Baudelaire: um lírico no auge do capitalismo. Tradução José Martins Barbosa, Hemerson Baptista. São Paulo: Brasiliense, 1989 (obras escolhidas v. 3). 
CHAUÍ, Marilena. O que é ser educador hoje? Da arte à ciência: a morte do educador. In: BRANDÃO, C. (Org.). O educador hoje. Rio de Janeiro: Graal, 1982, p. 51-70.

GAGNEBIN, Jeanne M. . História e Narração em W. Benjamin. São Paulo: Perspectiva: Fapesp, 1994.

TIBURI, Márcia. Uma outra história da razão. São Leopoldo: UNISINOS, 2003.

TÜRCKE, Christoph. Sociedade excitada: filosofia da sensação. Tradutores: Antônio A. S. Zuin et. al. Campinas, São Paulo: editora da Unicamp, 2010.

ZUIN, Antônio A. S.; PUCCI, Bruno; RAMOS-DE-OLIVEIRA, Newton. Adorno: o poder educativo do pensamento crítico. Petrópolis, Rio de Janeiro: Vozes, 1999. 